\title{
Mefloquine Improved Progressive Multifocal Leukoencephalopathy in a Patient with Systemic Lupus Erythematosus
}

\author{
Minako Beppu $^{1}$, Michi Kawamoto ${ }^{1}$, Souichi Nukuzuma ${ }^{2}$ and Nobuo Kohara ${ }^{1}$
}

\begin{abstract}
We describe a case of a 67-year-old man with systemic lupus erythematosus who presented with progressive left hemiplegia. Although the cerebral spinal fluid (CSF) polymerase chain reaction (PCR) for the JC virus was negative, a brain biopsy confirmed the diagnosis of progressive multifocal leukoencephalopathy (PML). The tapering of prednisone and the use of cidofovir could not arrest the disease progression. Administration of mefloquine stopped the extension of the lesion, and resulted in obvious clinical improvement. The CSF nested PCR for the JC virus also became negative. This widely used drug should be tried for the treatment of non-HIV PML.
\end{abstract}

Key words: progressive multifocal leukoencephalopathy, systemic lupus erythematosus, mefloquine

(Intern Med 51: 1245-1247, 2012)

(DOI: 10.2169/internalmedicine.51.6810)

\section{Introduction}

Progressive multifocal leukoencephalopathy (PML) is a fatal demyelinating disease caused by JC virus infections and is mainly seen in patients with AIDS. In patients with HIV, the use of highly active antiretroviral therapy (HAART) has reduced the mortality of patients with PML (1). With respect to PML in patients without HIV, there are currently no approved therapies, although cytosine arabinoside, $\alpha$-interferon, and cidofovir have been reported effective in some cases. Mefloquine, a widely used antimalarial agent, was recently reported to inhibit the JC virus infection in vitro (2) and produce some clinical improvement (3-5). Here, we report the beneficial effect of mefloquine in a case of PML associated with systemic lupus erythematosus (SLE).

\section{Case Report}

A 67-year-old man had experienced prolonged fever, arthritis, and nephritis. Laboratory tests were positive for anti-
DNA antibodies and hypocomplementemia. He was diagnosed as having SLE and administered prednisone $(20 \mathrm{mg}$ daily). Four months after the treatment, he noticed mild weakness in his left foot and the condition gradually worsened. A neurological examination on admission (five months after initiating prednisone therapy) revealed severe left lower limb weakness with increased deep tendon reflex and positive Babinski sign. The laboratory findings revealed mildly elevated CRP (2.0 mg/dL) with normal anti-ds DNA antibodies and complement levels. HIV was negative, and CSF showed normal cell counts and normal protein and glucose levels. CSF PCR tests for herpes simplex, varicella-zoster, Epstein-Barr, cytomegalovirus, and JC virus were all negative. Brain MRI showed a focal lesion in the white matter of the right frontal lobe, which was hyperintense on the T2weighted and FLAIR images and hypointense on the T1weighted images without contrast enhancement (Fig. 1A). There was no mass effect. As lupus cerebritis or tumefactive multiple sclerosis was considered probable, we performed intravenous methylprednisolone pulse therapy ( $1 \mathrm{~g} / \mathrm{day}$ for 3 days) followed by oral prednisone at a dosage of $1 \mathrm{mg} / \mathrm{kg}$. Two weeks later, however, his left lower limb paralysis

${ }^{1}$ Department of Neurology, Kobe City Medical Center General Hospital, Japan and ${ }^{2}$ Department of Microbiology, Kobe Institute of Health, Japan

Received for publication October 26, 2011; Accepted for publication January 22, 2012

Correspondence to Dr. Minako Beppu, bepumi550@gmail.com 

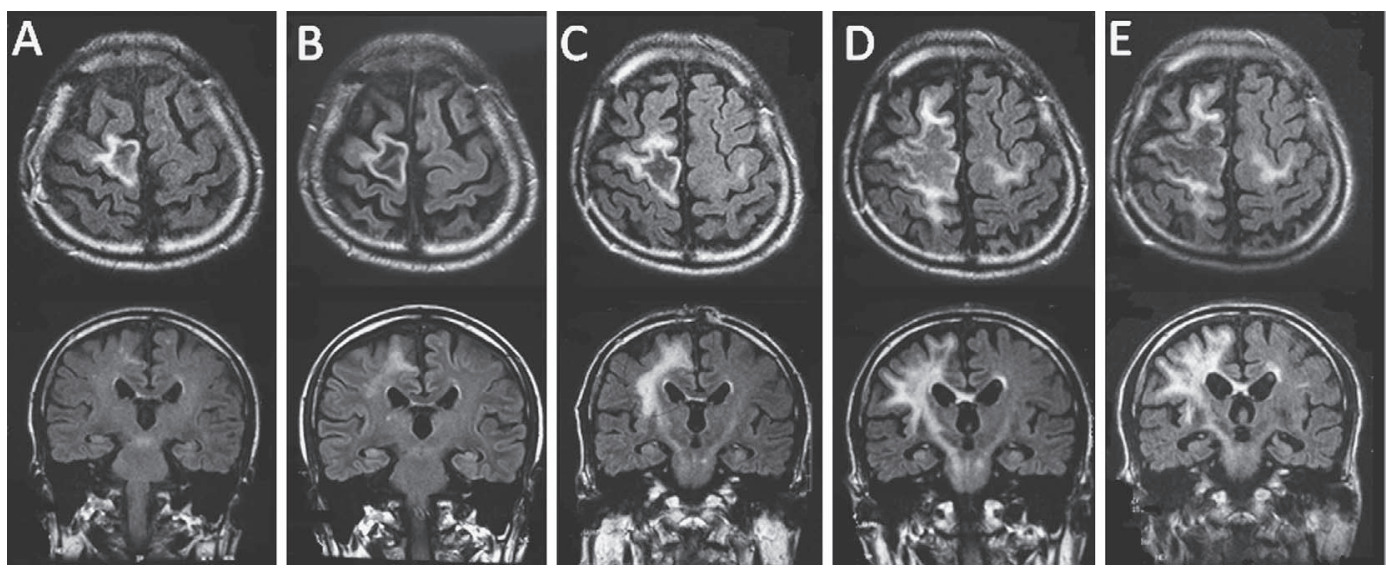

Figure 1. Changes on FLAIR MRI images. (A) Right frontal white matter lesions were identified on admission. (B) One month after admission the lesions had become extended. (C) Extension of the lesions and the presence of additional new white matter lesions in the left frontal lobe were identified at 2 months after admission. (D) MRI at the time clinical improvement began (one month after the start of mefloquine therapy- see Figure 2). E) MRI showing a cessation of the lesion expansion (one year after the start of the mefloquine therapy).
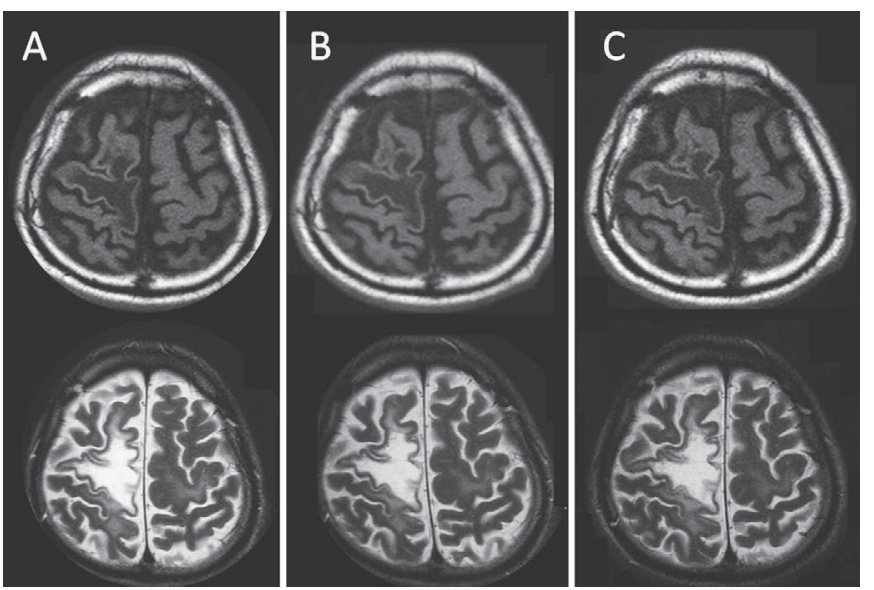

Figure 2. Follow-up T2WI and T1WI MRI images after the start of the mefloquine therapy. No obvious lesion extensions were found at 9 (A), 11 (B), or 13 weeks (C) after the start of mefloquine.

worsened and there was an extension of the lesion on MRI (Fig. 1B). In order to achieve a diagnosis, we performed a brain biopsy, which revealed left parietal lobe demyelination, oligodendrocytes with enlarged nuclei, and macrophage infiltration. Immunohistochemical staining for antibodies directed against simian virus 40 (SV40) large T-antigen, which cross-reacts with the JC virus, showed scattered positive staining of oligodendrocytes. PCR tests for the JC virus in the brain biopsy sample proved positive. The CSF sample taken at the onset was reanalyzed using the nested PCR method and proved positive for the JC virus. We accordingly diagnosed the lesion as PML.

The prednisone was subsequently tapered and cidofovir (5 $\mathrm{mg} / \mathrm{kg}$ ) was administered at bi-weekly intervals. However, the patient's left hemiplegia worsened, and in the subsequent two months he also developed right hemiplegia, dysphagia, and dysarthria. Extension of the lesion and the presence of additional new white matter lesions in the left frontal lobe were identified (Fig. 1C). We therefore started mefloquine therapy $1,100 \mathrm{mg}$ on the first day and then 275 mg weekly. Cidofovir medication was accordingly discontinued. After 2 weeks of therapy, the paralysis stopped progressing and the patient's general condition began to improve (Fig. 1D). The CSF nested PCR for the JC virus became negative after the start of the mefloquine therapy. The brain MRI revealed that the lesions had not extended further (Fig. 2). We continued the mefloquine medication for 7 months and then discontinued the treatment. During the treatment with mefloquine, the patient showed no sign of any adverse effects. One year after starting mefloquine therapy, the patient had experienced no relapse (Fig. 1D, 1E), and the CSF PCR for JC virus remained negative. The patient started to do ambulatory exercise, and he could do oral ingestion. Fourteen months after the initiation of treatment however, he died of pneumonia and sepsis.

\section{Discussion}

PML is a rare and often fatal demyelinating disorder that is secondary to central nervous system infection caused by reactivation of the JC virus. Although HIV infection remains the most common predisposing factor for PML, it can also occur as a complication of a chronic illness associated with secondary immunosuppression. Nearly two-thirds of patients with rheumatic disease have SLE (6). A retrospective population-based study that analyzed a health insurance database indicated that the incidence rate of PML in patients with SLE is 12.4 per 100,000 person-years (7). It is noteworthy that only the maintenance doses of corticosteroids could have developed PML $(8,9)$ suggesting that SLE itself is a risk factor for PML. 
The criterion standard for the diagnosis of PML is brain biopsy. However, some patients may not be able to tolerate brain biopsy or the lesions may be inaccessible. As an alternative to brain biopsy, the diagnosis of PML can be established by PCR detection of the JC virus DNA in the CSF, which has a sensitivity of approximately $80 \%(10,11)$. However, such testing can be negative in early PML. In fact, in the present case, the CSF PCR for the JC virus was negative, but the brain sample PCR and CSF reanalyzed by nested PCR proved positive. Such findings indicate if clinical suspicion of the disease remains high, CSF analysis should be repeated using a more sensitive method such as nested PCR.

To date, there have been only 3 case reports of patients with PML being treated with mefloquine $(3,4)$. Kishida and Tanaka (3) reported a patient with an umbilical cord blood transplant who showed favorable clinical, neuroradiological, and virological responses after treatment with mefloquine. A case of multiple sclerosis with developed PML after natalizumab infusions was improved by the removal of natalizumab with application of mefloquine and mirtazapine (4). Gofton et al. (5) recently described a patient with PML and sarcoidosis, showing cerebellar and brainstem involvement, whose clinical progression stopped just after the mefloquine treatment. These cases, as well as the present case, showed decreased JC viral DNA levels after the treatment. The recent mefloquine trial of PML patients, on the contrary, reported to fail to reduce JC viral DNA levels in the CSF (12). This trial included 21 HIV-positive patients, all of whom were taking highly active antiretroviral therapy (HAART), and three HIV-negative patients who had either cancer or rheumatoid disease. The background condition, status of HIV with HAART or non-HIV, might have affected the results. More cases should be tested to confirm whether mefloquine is effective for treading PML. Use of this widely used low-cost, and relatively safe drug should be attempted for the treatment of this intractable disease, especially non-HIV PML.
The authors state that they have no Conflict of Interest (COI).

\section{References}

1. Albrecht H, Hoffmann C, Degen $O$, et al. Highly active antiretroviral therapy significantly improves the prognosis of patients with HIV-associated progressive multifocal leukoencephalopathy. AIDS 12: 1149-1154, 1998.

2. Brickelmaier M, Lugovskoy A, Kartikeyan R, et al. Identification and characterization of mefloquine efficacy against JC virus in vitro. Antimicrob Agents Chemother 53: 1840-1849, 2009.

3. Kishida S, Tanaka K. Mefloquine treatment in a patient suffering from progressive multifocal leukoencephalopathy after umbilical cord blood transplant. Intern Med 49: 2509-2513, 2010.

4. Schroder A, Lee DH, Hellwig K, Lukas C, Linker RA, Gold R. Successful management of natalizumab-associated progressive multifocal leukoencephalopathy and immune reconstitution syndrome in a patient with multiple sclerosis. Arch Neurol 67: 13911394, 2010.

5. Gofton TE, Al-Khotani A, O'Farrell B, Ang LC, McLachlan RS. Mefloquine in the treatment of progressive multifocal leukoencephalopathy. J Neurol Neurosurg Psychiatry 82: 452-455, 2011.

6. Molloy ES, Calabrese LH. Progressive multifocal leukoencephalopathy in patients with rheumatic diseases: are patients with systemic lupus erythematosus at particular risk? Autoimmun Rev 8: 144-146, 2008.

7. Amend KL, Turnbull B, Foskett N, Napalkov P, Kurth T, Seeger $\mathrm{J}$. Incidence of progressive multifocal leukoencephalopathy in patients without HIV. Neurology 75: 1326-1332, 2010.

8. Itoh K, Kano T, Nagashio C, Mimori A, Kinoshita M, Sumiya M. Progressive multifocal leukoencephalopathy in patients with systemic lupus erythematosus. Arthritis Rheum 54: 1020-1022, 2006.

9. Reilmann R, Imai $T$, Ringelstein EB, et al. Remission of progressive multifocal leucoencephalopathy in SLE after treatment with cidofovir: a 4 year follow up. J Neurol Neurosurg Psychiatry 76: 1304-1305, 2005.

10. Cinque P, Koralnik IJ, Clifford DB. The evolving face of human immunodeficiency virus-related progressive multifocal leukoencephalopathy: defining a consensus terminology. J Neurovirol 9 Suppl 1: 88-92, 2003.

11. Hirsch HH, Meylan PR, Zimmerli W, Iten A, Battegay M, Erb P. HIV-1-infected patients with focal neurologic signs: diagnostic role of PCR for Toxoplasma gondii, Epstein-Barr virus, and JC virus. Clin Microbiol Infect 4: 577-584, 1998.

12. Friedman R. News from the AAN Annual Meeting: Malaria drug fails to fulfill promise in PML. Neurology Today 11: 8, 2011.

(C) 2012 The Japanese Society of Internal Medicine http://www.naika.or.jp/imindex.html 